\title{
Stress and coping with discrimination and stigmatization
}

\author{
Sophie Berjot ${ }^{1 *}$ and Nicolas Gillet ${ }^{2}$ \\ 1 Laboratoire de Psychologie Appliquée, Département de Psychologie, Université de Reims Champagne Ardenne, Reims, France \\ 2 Psychologie des Âges de la Vie, Département de Psychologie, Université François Rabelais, Tours, France
}

\author{
Edited by: \\ Jesus De la Fuente, University of \\ Almería, Spain \\ Reviewed by: \\ Jesus De la Fuente, University of \\ Almería, Spain \\ Kuan-Chung Chen, National University \\ of Tainan, Taiwan \\ *Correspondence: \\ Sophie Berjot, Laboratoire de \\ Psychologie Appliquée - EA 4298, \\ Département de Psychologie, \\ Université de Reims Champagne \\ Ardenne, 57 rue Pierre Taittinger, 51096 \\ Reims Cedex, France. \\ e-mail: sophie.berjot@univ-reims.fr
}

The aim of this article is to briefly review the literature on stigmatization and more generally identity threats, to focus more specifically of the way people appraise and cope with those threatening situations. Based on the transactional model of stress and coping of Lazarus and Folkman (1984), we propose a model of coping with identity threats that takes into accounts the principle characteristic of stigma, its devaluing aspect. We present a model with specific antecedents, a refined appraisal phase and a new classification of coping strategies based on the motives that may be elicited by the threatening situation, those of protecting and/or enhancing the personal and/or social identity.

Keywords: identity, coping, stress, appraisal, model
Originally, a stigma was a physical mark that was apposed on some persons to signal not only their lower status (e.g., prostitute, slave), but the fact that one should avoid them because of morality flaws, sicknesses or more generally because those person could be dangerous in a way or another. Today's conceptualizations have changed quite a lot, going from a single external mark that told people to avoid a person, to, nowadays, the possession (or the belief of it) of "some attribute or characteristic that conveys a social identity" that is devalued in a particular social context" (Crocker et al., 1998, p. 505). Now, one can be stigmatized because he merely belongs to a group that is devalued in a given society. This can be because one is a woman, poor or from a poor family, homosexual, from another culture, member of a minority or simply because one does not look like everybody else (e.g., too big, too tall, too small). All are stigmatizing "categories" that can be met in the school context.

The consequences of stigma are numerous, especially for the stigmatized. One of the most obvious and frequent consequence of stigmatization is the discrimination that often comes with it. This can be blatant aggressions or more subtle mistreatment such as receiving a lower grade than deserve, being ignored by teachers and peers (Fisher et al., 2000). But stigmatization can also have more subtle effects as stigmas can serve teachers to fulfill prophecies (Jussim and Harber, 2005; Jussim et al., 2009) and can also have deleterious effects on performance through stereotype threat effects (Steele and Aronson, 1995; Huguet and Régnier, 2007).

${ }^{1}$ We will use here the definitions of personal and social identity of Hogg (2003, p. 463). For Hogg, "social identity refers to commonalities among people within a group and differences between people in different groups and is associated with group behaviors." Personal identity refers to "self as distinct from other people or self as defined in terms of specific relationships with other individuals and is not associated with group behaviors." Note that for Hogg, social identity is a theory of the self. "This theory makes a distinction between the collective self (social identity), which is associated with group membership, group processes, and intergroup behaviors, and the individual self (personal identity), which is associated with close personal relations and idiosyncratic attributes of self."
All those consequences of stigmatization and discrimination have such deleterious effect on the individual (e.g., low self-esteem, anxiety, lower performance), that several authors have recently conceived stigma as a very powerful stressor (Crocker et al., 1998; Clark et al., 1999; Miller and Kaiser, 2001; Major and O'Brien, 2005). As such, many authors proposed to use or adapt models of stress to better understand how stigma affects people. Based on this logic and drawing on the literature on stigmatization, discrimination and more generally on identity, the aim of the present article is to propose a revised model of stress and coping with stigmatization by focusing on its principal characteristic, its devaluing aspect for identity.

\section{STIGMATIZATION AS A SOURCE OF STRESS}

The idea that people are active in responding to discrimination and stigmatization is not new. More than 50 years ago, Allport (1954) described how victims of discrimination used compensatory behaviors to cope with the discreditation of their identity. The Social Identity Theory (SIT) and its developments gave also a vision of the human being as being particularly active in reacting to various threats to identity and systematized those reactions into a coherent and fruitful theory (Tajfel, 1981; Tajfel and Turner, 1986; Blanz et al., 1998). More recently, other authors focused more on the effects of discrimination, and showed again that stigmatized individuals are not passive, respond actively to identity threats and are not condemned to get lower self-esteem (Crocker and Major, 1989; Branscombe et al., 1999; Schmitt and Branscombe, 2002).

The view that stigmatization, discrimination, and more generally identity threatening situations are important sources of stress was developed later, pointing not only at the immediate reactions of people under threats but on the effects of these threats on identity, health, physical reactions, and social functioning (Allison, 1998; Clark et al., 1999; Miller and Major, 2000; Miller and Kaiser, 2001). 
For instance, some studies showed that discrimination is associated with more physiological arousal and in particular, cardiovascular responses among stigmatized persons (see Harrell et al., 2003, for a review). In addition, a recent study by Richman et al. (2007) showed that Black men with a past experience with discrimination had a more acute physiological reaction to stressors than Whites (i.e., recall a past experience of feeling angry toward another person), suggesting that discrimination weakens stigmatized people in their ability to cope with other kind of stressors.

On a more psychological level, other studies showed that women declaring to be victim of sexism are more depressed (Kobrynowicz and Branscombe, 1997) and have a lower self-esteem (Swim et al., 2001) than women who do not perceive to be victims of sexism. This is also the case of other members of minority groups such as homosexuals (Diaz et al., 2001) or Black Americans (Branscombe et al., 1999) or of young students. For example, a study of Fisher et al. (2000) showed that white students (ranging from 13 to 19 years) reported less distress reactions to perceived discrimination from the institutional or the educational contexts than their African Americans, Hispanics, or Asians peers (Fisher et al., 2000).

\section{THE TRANSACTIONAL MODEL OF STRESS AND COPING}

According to Lazarus and Folkman (1984), "psychological stress is a particular relationship between the person and the environment that is appraised by the person as taxing or exceeding his or her resources and endangering his or her well-being" (Lazarus and Folkman, 1984, p. 19). This relationship goes through two important phases that are (1) cognitive appraisals and (2) coping.

Cognitive appraisal is the "process of categorizing an encounter, and its various facets, with respect to its significance for well-being" (Lazarus and Folkman, 1984, p. 31). Indeed, before actually coping with a situation, this one has to be cognitively evaluated as potentially stressful. This appraisal goes through two cognitive mechanisms which are primary and secondary appraisals. Primary appraisal is an assessment of what is at stake: "Am I in trouble or being benefited, now or in the future, and in what ways?" If the answer to this question is yes, then people categorize the situation as being a threat, a challenge or a loss. Loss refers to damages or harms that have already happened; threat and challenge appraisals can refer to past events or to anticipated ones. While threat suggests potential danger to one's well-being or self-esteem, challenge suggests that one focuses on the success, the social rewards and the personal growth that the situation could bring. It is important to note however that threat and challenge appraisals are not necessarily mutually exclusive. As stated by Lazarus and Folkman (1984), threat and challenge appraisals are not two ends of a single continuum. Although they are negatively correlated (Skinner and Brewer, 2002; Berjot and Girault-Lidvan, 2009), threat and challenge appraisals can occur simultaneously. For example, Folkman and Lazarus (1985) showed that students waiting for an exam appraised the upcoming event as particularly threatening and challenging.

Secondary appraisal is an assessment of coping resources and answers to the question: "Can I cope with this situation?" It indicates confidence in one's ability to cope with the situation because one has the resources to cope with it. Resources can be physical (e.g., health, energy), social (e.g., social support one can get from family, friends and social network), psychological (e.g., beliefs, self-esteem, perceived control, morale), or material (e.g., financial, tools).

Coping refers to "cognitive and behavioral efforts to master, reduce, or tolerate the internal and/or external demands that are created by the stressful transaction" (Folkman, 1984,p. 843; see also Folkman and Lazarus, 1980). Given the diversity of responses to stress that exist, most authors tried to make significant and meaningful categorizations (e.g., active versus passive or avoidant coping, see Suls and Fletcher, 1985; Roth and Cohen, 1986). Lazarus and Folkman (1984) proposed that coping serves two major functions. One is the regulation of emotions or distresses that come with the stressful situation (emotion-focused coping). The other is the management of the problem that is causing the stress by directly changing the elements of the stressful situation (problem-focused coping). Although both forms of coping are used in most stressful encounters, they are nevertheless dependent of the way one appraises the situation (i.e., as a threat and/or a challenge) and of the antecedents of the model. For example, Folkman and Lazarus, who analyzed 1300 stressful episodes reported by people, found that both forms of coping were used in most encounters. Nevertheless, people tended to use more problem-focused strategies when the situation was appraised as changeable and more emotion-focused strategies when the situation was appraised as not or less changeable (Folkman and Lazarus, 1980).

Lazarus and Folkman (1984) identified at least to broad categories of antecedents which will directly influence how people appraise and cope with the situation: those linked to the characteristics of the individual and those linked to the characteristics of the situation. Among the first ones, we can find, for example, commitments (which defines what is important for the person and so what is at skate in that situation), beliefs, such as beliefs about personal control (Folkman, 1984), and personal traits such as self-esteem (Rector and Roger, 1997). Among situational factors, we can find the novelty or the predictability of the situation, the uncertainty of the event, temporal factors (e.g., time generally enhance threat but can also leave some time to think through) or the ambiguity of the situation (Lazarus and Folkman, 1984).

\section{ADVANTAGES AND LIMITS OF THE TRANSACTIONAL MODEL OF STRESS FOR THE STUDY OF IDENTITY THREATS}

The use of transactional models of stress represents a real progress in that it permits to better explain and predict the variety of responses that people show when encountering discrimination and prejudice, as well as the effect of discrimination and prejudice on self-esteem and other adjustment related variables (Major et al., 2003a). They helped to systematize a large literature, highlighting the fact that stigmatized individual are not passive when confronting discrimination and that individual and situational factors interact to create a specific appraisal of the situation and engender specific coping strategies.

However, studies that tried to test or directly apply transactional models of stress often failed to show adequate results. For example, Barnes and Lightsey Jr. (2005) asked to 114 African Americans college students to answer several measures: a measure of perceived racism (i.e., how often participants experience different forms of discrimination), a measure of coping (i.e., the Coping Strategies 
Indicator, Amirkhan, 1990), and finally a measure of perceived stress (i.e., the PSS14, Cohen et al., 1983). The authors showed that perceiving discrimination is stressful. However, if coping was, as hypothesized, linked to stress, perception of discrimination did not predict coping, and coping did not moderate the effects of discrimination on stress.

Other authors have tried to test the transactional model of stress for the study of stereotype threat. Stereotype threat, which is "being at risk of confirming, as self-characteristic, a negative stereotype about one's group" (Steele and Aronson, 1995, p. 797), is another example of situations that can potentially threaten the identity of individuals (personal as well as social). In one study, Berjot et al. (2010) asked students from North African's origins and French to realize a task that was presented as diagnostic or not of abilities, and assessed afterward coping strategies and perceived stress. Results revealed that stereotype threat enhanced the use of emotion-focused strategies and decreased the use of problem-focused strategies for students from North African origins presented with a diagnostic task. However, the transactional model of stress failed to explain the whole process by which performance decreases for threatened individuals. First, only problem-focused coping partly mediated the relation between stereotype threat, while emotionfocused coping did not. Secondly, perceived stress was high for students from North African origin in both conditions (the threatening and the no-threatening). Therefore, the model could not specifically differentiate between the two kinds of stressors (i.e., the one that was involved by the fact that students were evaluated, and the one that implied a threat to their identity. In another experiment using the same paradigm and population, Berjot et al. (accepted) assessed primary appraisals, that is, how participants appraised the situation in terms of threat and/or challenge. Once again, results partly infirmed the transactional of model of stress, in that only challenge appraisals partly mediated the relation between stereotype threat and performance. Threat appraisals, that were operationalized according to the transactional model (i.e., harm or loss that are going to take place, and that suggest potential danger to one's well-being or self-esteem (Lazarus and Folkman, 1984; Lazarus, 1991; Skinner and Brewer, 2002) did not explained the relation. The reason is that the transactional definition of threat appraisals may be too global and not focused on threats to the identity (personal and/or social). Because stereotype threat is a threat to the social and personal aspect of identity and not to the global well-being or the self, results failed to confirm the adequacy of the transactional model.

\section{THE MODEL OF STRESS AND COPING WITH STIGMA AND IDENTITY THREATS}

Although the studies reported above did showed that stress and coping frameworks can effectively be useful to explain how people react to threats to their identity (e.g., stereotype threat, discrimination, prejudice), they also showed that those models need some refinements to better adjust to the specificities of the situations that stigmatized persons have to face. First, one has to take into account the main characteristic of stigma, its devaluing aspect for identity. Indeed, as stated by Crocker et al. (1998), stigmatized individuals are often devalued in society, in numerous situations. This can be unconscious, as this is the case with activation processes
(Wheeler and Petty, 2001), or more conscious as when a stigmatized person is in a situation where the negative stereotype that is associated with his group could apply and/or be confirmed (Skrypneck and Snyder, 1982; Steele and Aronson, 1995; Jussim et al., 2000). As shown by numerous studies, people do not cope with identity threatening situations as they do with situations that do not involve identity. Although both kinds of situations have to be coped with, they are nevertheless qualitatively distinct and need to be distinguished in their effects and processes. In particular, it seems to us that it is necessary to distinguish between what is tangible in a situation and that can be coped with (e.g., with traditional coping strategies), from what the situation means for identity. Indeed, coping with the consequences of discrimination (i.e., coping with the fact that one refuses me a job or a flat) is not exactly the same thing than coping with what it means for my identity (i.e., I feel like I am nobody, I feel that members of my group are insulted, etc.). If I can cope with the fact that an employer refuses me a job because I am a woman (by acting on the stressor, by "planning my actions" as models of coping would propose), how do I cope with the fact that my identity (personal and/or social) is threatened?

The model we propose here applies more specifically to those less tangible threats that are threats to identity (Berjot et al., 2008). We propose to keep all the different phases of the model (antecedents, appraisal, and coping) but make some refinements to adapt them to the specificities of identity relevant situations. In particular, as we will see, we propose to take into account both aspects of identity (personal and social) and the motive that are elicited when those aspects of identity are threatened or challenged (see Figure 1).

\section{ANTECEDENTS}

The transactional model of stress classifies antecedents into personal and situational factors (Lazarus and Folkman, 1984). We propose here to keep the two categories defined by Lazarus and Folkman (1984) and add a third one which takes into account the characteristics of stigma. Note that if most of the variables identified by the transactional models as influencing appraisals have not been tested yet in the context of stigmatization or identity threats, it seems plausible that they could also be pertinent for those specific threats.

\section{CHARACTERISTICS OF STIGMA}

Because of the high number of stigmas, it is necessary to classify them according to some criterion. One of the earlier is the wellknown classification of Goffman (1963) who distinguished between tribal stigmas (e.g., racial and religious identities), abominations of the body (e.g., physical disabilities), and blemishes of individual character (e.g., addictions, mental illness, homosexuality). But this way of categorizing stigmas is more based on similarities between stigmas than on real shared characteristics that differentiate different stigmas and could explain (1) how people act toward stigmatized people and/or (2) how stigmatized individuals react to discrimination and exclusion. Although some studies tried to find pertinent classifications of stigmas (see for example, Weiner et al., 1988; Frable, 1993; Deaux et al., 1995), it is essentially the one proposed by Crocker et al. (1998) that is used nowadays. According to the authors, stigmas can on one side be visible or not visible, and on the other side be controllable or uncontrollable. 


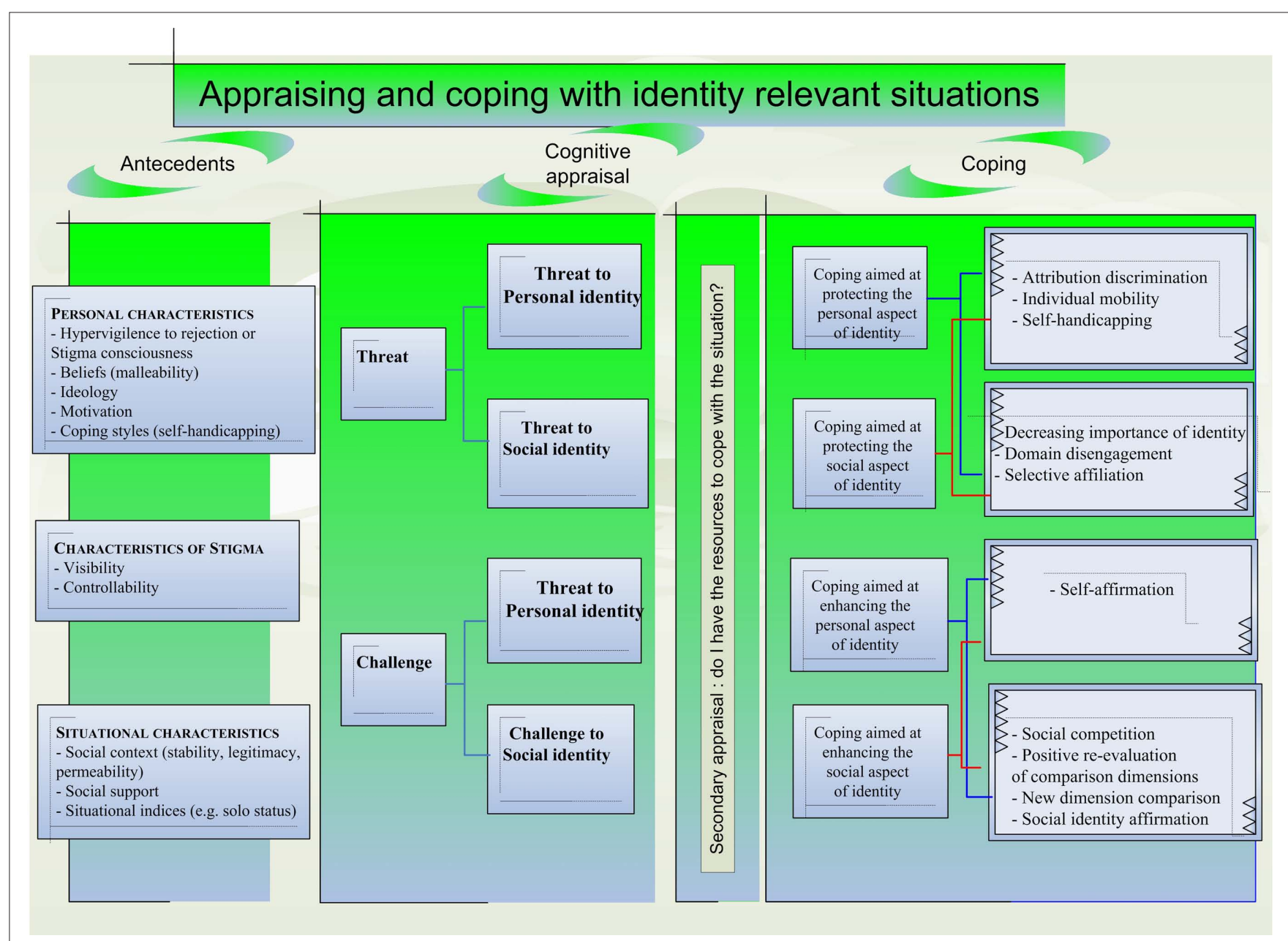

FIGURE 1 | Appraising and coping with identity relevant situations.

Visibility refers to the fact that one can easily and visually classify (or not) a stigmatized person because of his external aspect. So, women, Blacks, physically disabled persons, people suffering of obesity all possess a visible stigma. Homosexuals, people suffering from certain sicknesses such as HIV or diabetes, possess a nonvisible stigma. Note here that this dimension can be sometimes not as impermeable as it seems. So on the one hand, stigmatized people can decide to make their group belonging visible by saying it to others or by the use of external indices such as clothing, or non-verbal behaviors. On the other hand, people can also infer that a person is homosexual, poor, or sick by the observation of those indices.

Controllability refers to the fact that the origin or the issue of a stigma is (or not) controllable, that is (1) that the stigmatized person is responsible for the acquisition of the stigma (e.g., being fat, being physically disabled because of a car accident that one was responsible for) and/or (2) that the stigmatized person could do something to get rid of the stigma (e.g., could go on diet if he/she is fat, could find some work if he/she is jobless or poor). Again, note here that this dimension should be understood on a continuum. The categorization is not that easy to make for certain stigmas such as homosexuality or poverty because they largely depend on the beliefs we have about the origins of the stigma. For example, according to the way we think about the origins of poverty (as something entirely due to personal lacks and bad choices or principally due to socio-economical characteristics), we will think that this stigma is more or less controllable. Because the explanations we give for the reasons of being stigmatized are different according to the time and cultures, it may be important not to take for granted that certain stigmas are, or not, controllable. For example, while stereotypes about those who are poor are, in the US, mostly internal (e.g., poor people are poor because they do not work, they are described as lazy), stereotypes held in other countries such as France are internal and external (e.g., poor people are described as less smart but also courageous; Berjot and Drozda-Senkowska, 2007).

Controllability seems to be a pertinent categorization because it seems to influence attitudes toward stigmatized individuals (Hegarty and Golden, 2008). For instance, some studies showed that people who possess a controllable stigma are more rejected and prejudiced against than those possessing an uncontrollable stigma (Weiner et al., 1988; Crocker et al., 1998), but also are more likely to evoke pity and are less likely to receive help from others (Weiner et al., 1988; Menec and Perry, 1998). This is particularly the case of people suffering of obesity who are blamed for being fat and held responsible for their condition (Crandall, 1994). 


\section{PERSONAL CHARACTERISTICS}

Among the characteristics of the person that could have an impact on appraisal, we propose to focus on those that were the most studied in the stigmatization and identity literature. This is not to say that those highlighted by the transactional model could not fit. Variables such as self-efficacy or optimism have been shown to impact appraisal and or coping, in general and in identity relevant situations. For example, Kaiser and Miller (2004) showed that optimistic women tended to make more benign appraisals of the consequences of confronting sexism, appraisals that in turn predicted actual responses to prejudice.

Stigmatized individuals can vary in the degree they recognized or detect discrimination in their environment. They can be for example hyper-vigilant to rejection, that is, as described by Mendoza-Denton et al. (2002), be very sensitive to environmental cues that could be indices of rejection based on their race. They can also be, as showed by Pinel, more or less high in stigma consciousness. According to the author, stigmatized people differ in the way they expect to be judged and treated on the basis of the stereotypes associated with their group membership (Pinel, 1999, 2002). According to their sensibility to rejection or on their stigma consciousness, stigmatized people will then appraise identity relevant situations differently.

Another personal variable that could also moderate the impact of potentially threatening situations on the way people appraise and react to them is the implicit theories people have on their selves. According to Dweck (1999), aspects of self (personality, intelligence, morality, etc.) can be conceived as fixed, non-malleable trait-like entities (entity theory) or as malleable entities that can be changed and developed (incremental theory). Those theories structure the way people understand and react to human action and outcomes, in particular to negative social feedbacks. For example, Hong et al. (1999) showed that undergraduate university students who believed that intelligence was malleable (incremental theorists) were more likely to take remedial actions when faced with setbacks than students who believed that intelligence was not malleable. This effect was mediated by attributions for failure. Incrementalists attributed more their failure to their lack of efforts than entitatists. In another series of experiments, Nussbaum and Dweck (2008) showed that implicit theories have a direct effect on the strategies people used when faced with identity threats. While entitatists opted for defensive self-esteem repair (here, downward comparison), incrementalists opted for a more self-enhancing strategy (i.e., upward comparison). To test this idea that failure or threat of failure is more threatening for entitatists than for incrementalists, Aronson et al. (2002) trained Black and White student to see intelligence as malleable rather than fixed. Results showed that Black students who saw intelligence as malleable showed greater performance than those who were not trained to see it as malleable. More recently, and on another aspect of self, Rattan and Dweck (2010) showed that the way University undergraduates from minorities (African Americans, Latino Americans) think of their personality predicted their decision (or not) to confront prejudice. Those who believed that personality can be changed (incrementalists) declared confronting prejudice more that those who believed that personality is fixed and cannot be modified (entitatists).
As this is also the case with traditional strategies, one can also think that some coping strategies can be so stable that they can act as personality characteristics and directly act upon appraisals by interacting with situational cues. This is for example the case of self-handicapping that can be a stable characteristic. As such, some studies showed that some people self-handicap more than others (called high self-handicappers; see Rhodewalt, 1990 for a review). That characteristic is so powerful that high self-handicappers tend to self-handicap even in non-threatening situations. This was shown for example by Finez et al. (in press) with athletes who had to perform a motor task designed to detect their physical ability (high ego-threatening condition) or provide pre-testing data for an upcoming study (low ego-threatening condition). Results showed that high self-handicappers who also had low self-esteem engaged in self-handicapping even in a non-threatening situation.

Finally, another variable that seem promising but does not have been really explored is motivation. Hodgins and Knee (2002) for example have proposed a model that posits that individuals' motivation influences their ability to experience events without defensiveness. Specifically, the authors considered that autonomous and controlled motivation orientations (see Deci and Ryan, 2008) predict threat and defense. Autonomous motivation refers to engaging in an activity out of pleasure and/or volition and choice. In contrast, controlled motivation is defined as engaging in an activity for internal (e.g., guilt) or external pressure (e.g., external rewards). Results from past studies (e.g., Knee et al., 2005; Hodgins et al., 2006) revealed that individuals who are autonomously motivated are less defensive than those displaying controlled motivation especially because autonomous motivation is positively associated with integrated and secure self-processes (e.g., self-evaluation, selfawareness, self-actualization; see Deci and Ryan, 1985). Hodgins et al. (2010) used motivation priming to examine the links between motivation, defense, and performance in a sample of 77 undergraduates. Participants were exposed to a structured stressful interview with moderately high social threat and then, were asked to give a speech which was videotaped to evaluate their performance. The study included multiple objective consequences to assess threat response such as verbal defense, response latency, response length, fake smiling, vocal fundamental frequency, cardiac reactivity, and vascular resistance. Results showed that relative to controlled motivation, autonomous motivation lowers threat response (e.g., longer interview responses, less acoustic vocal fundamental frequency). In addition, the effect of motivation on performance was mediated by threat response. Specifically, autonomous motivation decreases threat response, that in turn, predicts higher levels of performance. Taken together, these studies provide evidence for the importance of autonomous motivation in the prediction of threat response and subsequent task performance.

\section{SITUATIONAL CHARACTERISTICS}

Situational characteristics are characteristics of the environment the person lives in and that could modify how he or she appraises and copes with the situation. If some characteristics issued from general stress and coping frameworks can again be pertinent (e.g., controllability of the situation), others are particularly pertinent in the context of identity threats. Among them, we can firstly identify those characteristics of the social context that directly impact the 
choice of coping strategies such as the stability of the social context (i.e., if the position of the group in society is perceived as stable), the legitimacy of the group status and its position in society (i.e., is the status of my group perceived as being legitimate or not?), as well as the permeability of the frontiers of my group (i.e., can I go from my revalorized group to another, more valued group). Those characteristics, highlighted by the SIT and the self-categorization theory tenants (Tajfel and Turner, 1986; Turner et al., 1987; Mummendey et al., 1999) showed to be quite predictive of actual coping strategies.

More generally, the context can also vary according to the number of indices that can inform stigmatized persons that the situation can be potentially threatening for their identity (Major et al., 2003b). Among those factors, we can cite the fact that one can be the only representant of his social group in a context (e.g., solo status or token, see Inzlicht and Ben-Zeev, 2000; Sekaquaptewa and Thompson, 2002; Inzlicht et al., 2006). For example, Inzlicht and Ben-Zeev (2000) asked women to complete a difficult Math test in different configuration of men/women ratios. Results showed that women performed less well when in minority and that their performance were proportional to the number of males in the group.

Social support from other in-group members can also help in identity threatening situations. They are a important resource for people who have to deal with threat in that they can bring information, help, share emotions and experiences about painful situations, or to enact specific strategies (Haslam et al., 2005; Bourguignon et al., 2006). But they permit also in-group identification. As shown by Schmitt and Branscombe (2002), group identification can be a resource to cope with identity threats such as discrimination. In their model, the authors state that discrimination enhances group identification which in turn, protects self-esteem.

\section{APPRAISALS}

If the appraisal phase is recognized in the stigmatization literature as being very important, the applications or the modifications of the transactional model that were done by the authors usually underscore three things that have to be taken into account if we want to understand the specificities of identity relevant situations: (1) the fact that there is not always something at stake for all individuals in all identity relevant situations, (2) the fact that those situations do not represent a threat for everyone and can be sometimes be appraised as challenges, and (3) the fact that those situations can threaten/challenge one or both aspects of identity ${ }^{2}$.

One of the reasons why those three things have tended to be neglected is that very often, authors have tended to consider stigmatization, discrimination, and situations that more generally are relevant for identity, as inherently threatening. This is the case of discrimination and prejudice but also of other kinds of situations and manipulations such as giving a negative feedback on an important and self-defining dimension (e.g., academics, sports). Added to the fact that few tools permit to assess the threatening

${ }^{2}$ Note that our model doesn't take into account the many forms that social identity can take, such as highlighted by Ashmore et al. (2004). So, social identity can be threatened because one is placed (or not) by others in a specific category (selfcategorization), because one's group is not positively perceived (by oneself or by others), because one's group is particularly important for self-definition, because one's is particularly and emotionally attached to the group, etc. (see Ashmore et al., 2004, for more details). nature of a situation, it is not surprising that few studies showed if and how a situation is appraised as threatening. More frequently, threat appraisals are deduced from the observation of some of its side effects such as specific coping strategies or lower self-esteem. However, some authors did try to assess appraisals. For example, several studies, using physiological measures, did show that situations such as stereotype threat or threats to social identity are appraised more as threats and less as challenges (Blascovich et al., 2000, 2001; Scheepers and Ellemers, 2005; Osborne, 2006, 2007).

On the other hand, and certainly for the same reasons, few studies focused on the potential for challenge of some identity relevant situations. Some authors have nevertheless showed that some people appraise identity relevant situations as a challenges and opportunities to enhance their identity. This is for example the case of members of low status groups who try to modify the stereotype held by members of a relevant out-group in a favorable direction (Klein and Azzi, 2001) or of Black students, highly identified to academics, who voluntary expose themselves to an evaluative situation when under stereotype threat (Cohen and Garcia, 2005). Challenge appraisal, contrary to threat appraisal helps to focus on the positive side of the situation and on the benefit that one can get from a success. As such, challenge appraisal might relief pressure and for example facilitate performance. This is for example what showed a study from Alter et al. (2010). In their experiment the authors showed that Black school children who had to report their race before performing a math test performed better when the test was framed as a challenge (emphasizing the role of the test in improving their general mathematical abilities) than a threat (emphasizing the diagnostic nature of the test).

Another surprising aspect of past research is that often, authors tend to focus on one or the other aspect of identity, and more rarely on both (personal or social) or on their links. Research on stigmatization showed however that the frontier between the personal and the social aspects of identity is thinner than we can imagine. This is the case of stigmatization, which is traditionally considered as a threat to the social aspect of identity because one belongs to a group that serves to maintain a positive social identity. But as Schmitt and Branscombe (2002) stated recently about the protective effects of the attribution to discrimination (i.e., attributing a negative treatment to the prejudice of someone else: see Crocker and Major, 1989), the fact that we belong to groups is important for the definition of who we are and as such, is a part of self-definition. Therefore, threats to group membership also threaten the personal aspect of identity (Schmitt and Branscombe, 2002). This is also the case of a lot of other situations that do not represent a threat for only one aspect of identity. This is the case for example of stereotype threat, which is, as stated by the authors (Steele and Aronson, 1995) a threat to the personal and the social aspect of identity. Depending on the way one manipulates stereotype threat, one, the other or both aspects can be threatened (Berjot, 2003; Berjot and DrozdaSenkowska, 2003; Shapiro and Neuberg, 2007; Wout et al., 2008).

According to our model, a situation into which identity is perceived as being at stake, can threaten and/or challenge a basic self motive, that of maintaining, protecting or enhancing the self (Sedikides and Strube, 1997; Baumeister, 1998), whether individual or collective. So, individuals will ask themselves "can my identity (personal and/or social) be called into question, devalued, or on the 
contrary enhanced, praised, and become more positive?" Put otherwise, is this situation a threat and/or a challenge to my personal and/or my social identity ${ }^{3}$.

This conceptualization of appraisal implies that we can make two important assumptions. The first one is that, depending on the individual and on the context, a situation may well be appraised as a threat and a challenge. As in the transactional model, threat and challenge are two separate appraisals that can be made simultaneously in a situation (Lazarus and Folkman, 1984; Skinner and Brewer, 2002; Berjot and Girault-Lidvan, 2009). The second thing is that, as we mentioned earlier, a situation can threaten or challenge one, the other or both aspects of identity, again, depending on the individual, its group characteristics and the situation.

Those assumptions were tested in a series of studies which first aim was to develop and validate a scale that measured how individuals appraise a situation in which their identity was at stake; as a threat and/or a challenge to their personal and/or social identity (Berjot et al., 2009). In one study, we compared people suffering of obesity with people from North African origins in the way they appraised discrimination. Results showed that while people suffering from obesity principally appraised discrimination as a threat to the personal aspect of their identity, people from North African origins appraised it as a threat and a challenge to the social aspect of their identity. We can then see here, that some groups, certainly because of the social support that their group identification can offer, appraise discrimination both as a threat and a challenge. On the other hand, other groups such as fat people, who are not identified with their in-group, and who bear a controllable stigma, appraise discrimination principally in terms of threat to the personal aspect of their identity.

\section{COPING}

It is evident that the strategies highlighted by the transactional model of stress to cope with standard or "regular" situations are not the same than those used when having to cope with identity threats, such as those used to cope with stigmatization or with

${ }^{3}$ Note here that the process of appraisal implies that the potentially threatening situation have been perceived and recognized. The interaction between personal and situational factors, will or will not elicit appraisal. A situation that is not recognized as potentially threatening or at least pertinent for identity will not be processed consciously and so is not described in our model.

\section{Table 1 | Proposition for a classification of some of identity} management strategies.

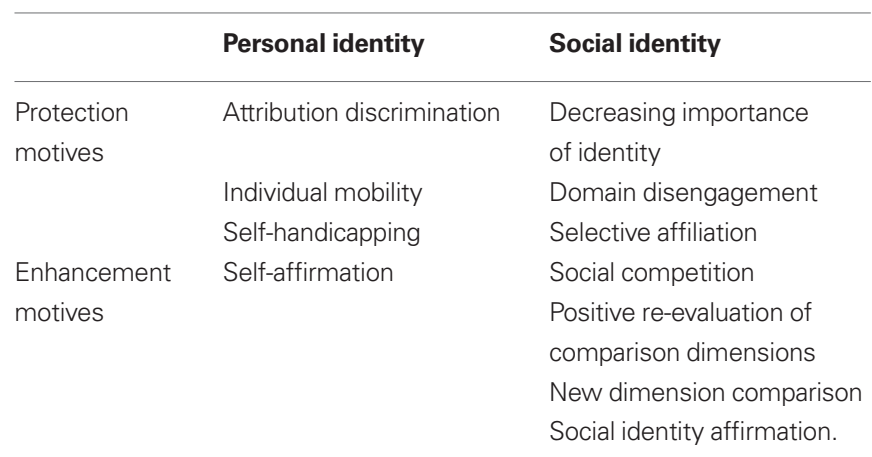

other identity threatening situations (e.g., like exams, negative feedbacks). One strategy is to try to fit identity management strategies into actual categorizations. This the strategy used for example by Miller and Kaiser (2001) who tried to fit identity management strategies into the Compas et al.'s (2001) categorization. This categorization proposes to classify voluntary coping responses into engagement or disengagement coping with the stressful event or problem. Engagement and disengagement coping can then be aimed at either gaining primary control (i.e., efforts directed toward the problem and the emotional reactions that it provokes) or secondary control (i.e., efforts to adapt to the situation). If this way of doing had resolved some problems linked to that fact that emotion- and problem-focused copings were sometimes difficult to disentangle (Compas et al., 2001), it does not solve the problem of the specificities of identity management strategies and do not answer to the question of the functions of coping with identity threats ${ }^{4}$. Put otherwise, why people use specific identity management strategies? One way to answer to this question is to refer to the motives which may be triggered by specific appraisals, that is to protect and/or enhance the personal and/or social aspects of identity. Remember that people are motivated to protect their identity but also, when possible, to enhance it, be it personal and/or social (Turner, 1982; Gaertner et al., 2002; Hogg, 2003). Indeed, self-enhancement is a very powerful motive (Sedikides, 1993; Sedikides and Strube, 1997) that guides people to enhance as often as possible their personal identity but also their social identity (Hogg, 2003).

So the categorization we propose to use here is directly based on the motives that are elicited by the appraisal made in a specific situation, that is, strategies aimed at protecting the personal identity, strategies aimed at protecting the social identity, strategies aimed at enhancing the personal identity and strategies aimed a enhancing the social identity. Note that this proposition, as many others, is not the panacea, in that certain strategies permit to fulfill different motives. As we will see, some strategies can be used for one, or another motive.

\section{STRATEGIES AIMED AT PROTECTING THE PERSONAL ASPECT OF IDENTITY}

In that category, one can put all identity management strategies that are aimed at protecting the characteristics that defines us as a person. They can be used in a group context (as when dealing with discrimination or with group relations) as well as in a personal context.

Attribution to discrimination is one of the strategies that people can use to cope with discrimination. This strategy, first defined by Crocker and Major (1989) protect self-esteem of members of stigmatized groups because they attribute "negative feedback or poor outcomes to the prejudiced attitudes of others toward the group" (Crocker and Major, 1989, p. 612). Note that according to the authors, this attribution must be perceived as unjust and as

\footnotetext{
${ }^{4}$ Many other classifications of identity management strategies have been proposed, mostly based on actual coping strategies classifications. We can cite for example the taxonomy of strategies derived from the SIT proposed by Blanz et al. (1998) as being either behavioral or cognitive and either individual or collective (classification based on the characteristics of the coping answer).
} 
coming from someone else to permit the discounting of self-blame (Major et al., 2003b). An attribution made to group membership but that is judged to be fair or justified (as this is the case for example for overweight women who regularly blame themselves for being overweight, see Crocker et al., 1993) will not permit a restoration of self-esteem.

Another strategy that can be used to protect personal identity is individual mobility. Originally conceived in the context of intergroup relation by the tenants of the SIT (Tajfel, 1978), this strategy consists at trying to leave the negatively viewed in-group to integrate a new and positive one. This is a strategy likely to be preferred by individuals who categorize themselves at the personal level in a given context and aims at protecting the personal aspect of identity (Branscombe and Ellemers, 1998). This strategy resembles that described by Deaux and Ethier (1998), the "elimination of identity." The authors define it as the abandon or the elimination of a social identification. Note that this strategy is likely to be used after numerous threat to the identity and more rarely after one encounter with prejudice (Deaux and Ethier, 1998).

One last example of a strategy aimed at protecting the individual self can be self-handicapping. This strategy consists of adopting (behavioral self-handicapping) or claiming (claimed self-handicapping) impediments to success prior to performing (Jones and Berglas, 1978; Hirt et al., 1991; Finez et al., 2008), in order to protect one's image in the event of failure (self-protective motives) or to enhance it in the event of success (self-enhancement motives; Jones and Berglas, 1978). So, this strategy can serve both motives, that of protecting or of enhancing the self. Even if this strategy is not specifically used to cope with group threats, some authors did assess its use in a context of social identity threats. For example, Steele and Aronson (1995) showed that Black students who had to take a task presented as diagnostic of abilities self-handicapped more (i.e., claimed they had less hours of sleep the night before and that they had less ability to focus) than Black students who had to take a non-diagnostic task or than White students. This use of self-handicapping in a stereotype threat paradigm was latter replicated in the sport context by Stone (2002) for behavioral self-handicapping. Note that the manipulation of stereotype threat used in those two studies threatens more the personal aspect of identity than the social aspect (see Shapiro and Neuberg, 2007, for a discussion on the effects of the different manipulation of stereotype threat on identity). If self-handicapping was principally studied in the context of personal identity threats, it is nevertheless possible that this strategy can be used to protect the social aspect of identity.

\section{STRATEGIES AIMED AT PROTECTING THE SOCIAL ASPECT OF IDENTITY}

This set of strategies groups the different attempts to protect the social aspect of identity, that is, to protect the positivity of the existing group membership. Among those, we can find for example the decrease of the importance attached to an identity. One still identifies with his group but places less importance on this identity to define himself (Deaux and Ethier, 1998). This renders identity relevant situations less threatening.

This strategy is close of another one, the "domain disengagement" (Crocker and Major, 1989; Steele, 1997) which consists for members of stigmatized groups "to selectively devaluing or regarding as less important for the self-definition, the performance dimension on which they or their group faire(s) poorly, and selectively valuing those dimensions on which they or their group excel(s)" (Crocker and Major, 1989, p. 616). This strategy will be used when a domain into which we decide to enter is threatening because of the stereotype associated with the group membership (as for example women studying math in prestigious universities). Note that this strategy can also be used to protect the personal aspect of identity when one regularly receives negative feedbacks on a valued domain.

Selective affiliation is another strategy that can be used to protect the social aspect of identity. This strategy consists at intensifying contacts with in-group members to find social support and a revalorization of one's identity (Deaux and Ethier, 1998; Siegal et al., 1998).

\section{STRATEGIES AIMED AT ENHANCING THE SOCIAL ASPECT OF IDENTITY}

Among the strategies aimed at enhancing the social aspect of identity, we can cite social competition (Tajfel, 1978), that is, competing for a positive evaluation of the in-group by specific actions and behaviors. Another set of strategies that can help to enhance social identity is the social creativity (Tajfel, 1978).

One can for example re-evaluate some threatened dimensions and declare them/perceive them as positive instead of negative or one can also choose another comparison dimension on which the in-group have a higher status or excels. This last strategy resembles the "originality" strategy described by Lemaine (1974). In one of his experiment, Lemaine (1974) observed children during a summer camp after having formed two groups. Each group had to build a hut in the wood which would be afterward rewarded. But one of the two groups was given a handicap that prevented them to build a real hut (i.e., impossibility to build a ladder). The authors observed that the handicapped group often introduced another criterion of judgment to differentiate themselves of the others by doing "something different" (e.g., build a garden) and, even if admitting the superiority of the other group on the original criterion (i.e., the hut), asked to be recognized on the new criterion which they had introduced.

Finally, another strategy that can be used to enhance social identity is to affirm one's social identity by direct claim or behavior toward others. This strategy does not consist at finding a new dimension but at showing the existence of this identity (in all its aspects). Deaux and Ethier (1998) called this strategy "reaffirmation." According to the authors, reaffirmation "refers to identity work in which the person proclaims or reasserts an identity that is already part of her or his self-definition" (Deaux and Ethier, 1998, p. 309).

\section{STRATEGIES AIMED AT ENHANCING THE PERSONAL ASPECT OF IDENTITY}

Bias or self-enhancing processes are numerous (Sedikides and Strube, 1997; Sedikides and Gregg, 2003). But explicit coping strategies aimed at enhancing the personal aspect of identity are scarcer. The most known is self-affirmation (Steele, 1988), which is the

${ }^{5}$ Note that this strategy is most often temporary. The continual use of this strategy to protect identity can lead, according to Steele (1997) to a chronic state of "domain disidentification;" one leaves definitively the threatening domain. 
affirmation (in one's own eyes or in the eyes of others) of ones personal qualities. If self-affirmation seems to have a positive impact on cognitive processes (e.g., resistance to persuasion, lower cognitive dissonance), this strategy is quite effective to cope with identity threats (Steele, 1988; McQueen and Klein, 2006). Self-affirmation enables for example to negatively stereotyped group members to perceive others as being less prejudiced (Adams et al., 2006) or to cope efficiently to stereotype threat (Martens et al., 2005).

Self-affirmation can also express itself via compensation (compensatory self-enhancement, see Baumeister and Jones, 1978; Baumeister, 1982). In that case, people will show to the other person that they have other qualities or positive characteristics. For example, Jarry and Kossert (2007) showed that women threatened on their self-esteem (through a negative feedback on an intellectual task) and who had viewed media images featuring thin models, declared themselves more pleased with their appearance than not threatened women (having received positive feedback) who had not viewed such images.

Another strategy that can be thought of as a strategy aimed at protecting the personal aspect of identity is "basking in reflected glory" (Cialdini and Richardson, 1980). Although, this strategy can be used in a very limited number of situations (i.e., when someone else has outperform us).

\section{GOING FURTHER: HOW EMOTIONS COULD FIT IN THIS MODEL?}

One last issue that we did not discuss is the question of emotions. This could be viewed as a lack of the proposed model but we believe that this question is quite premature at this point. We can only propose some broad hypotheses because several major problems have to be resolved before introducing emotions in the model.

The first one concerns the way emotions are defined and the implications for measuring. If authors do not always agree with the definition of emotions, almost all agree to consider that emotions are short but dynamic processes (Lazarus, 1999, 2006; Sander and Scherer, 2009). Emotions are elicited in response to an event and depends on the event's characteristics. So they may change as the event unfold as different appraisals are made and different actions are undertaken. As Lazarus puts it, "when there is stress, there are also emotions" (Lazarus, 1999, p. 35). For our model, this implies that emotions can be expressed and will surely be different (1) when encountering a situation (and be dependant on its characteristics such as its novelty and ambiguity, and on one's characteristics), (2) after primary appraisal (and depend on the kind of appraisal which is made), (3) after secondary appraisal (and depend on the resources individuals think they have) and (4) after coping (and depend on the actions taken and their efficiency). This complicates a lot the model. Some authors have shown for example that emotions are not the same depending on the phase of the process. For example, Marx and Stapel (2006) told Dutch undergraduates that they have to complete a test that was presented as a diagnostic task (or not) for examining Math abilities. Half of the participants completed an emotion measure before taking the test, while the other half completed the measure after the test. Results showed that females in the stereotype threat condition reported more anxiety before the test (i.e., afraid, anxious, confident, distressed, nervous, scared, uncertain) and more frustration after the test (i.e., angry, ashamed, frustrated, happy, irritable, unintelligent, upset) than their male counterparts.

The second point concerns the fact that even if emotions are recognized as playing a very important role in identity relevant situations, there is not an extensive literature on their place and role in the process of coping with identity threats. Moreover, authors have more often focused on global emotions (e.g., positive versus negative emotions, affective states, mood) instead of on specific emotions (Tracy and Robins, 2004; Marx and Stapel, 2006). So, except the fact that identity threats are emotionally painful, and conduct to lower self-esteem and well-being, we know little about what specific emotions are experienced in different kinds of identity relevant situations.

The third point concerns the specificities of identity relevant situations. It seems that emotions per se (i.e., basic emotions) are not totally suitable for the study of identity related issues. Indeed, as stated by Tracy and Robins (2004), if identity relevant situations have the potential to elicit basic emotions, they also have the unique potential to elicit self-conscious emotions (e.g., shame, guilt, pride). Self-conscious emotions are emotions of the self. They are elicited when people become aware of the fact that they lived up or failed to lived up self-standards (Tracy and Robins, 2004) when they make inferences about other people's evaluations about them (Tangney, 1992; Leary, 2007). According to Tracy and Robins (2004), self-conscious emotions require self-awareness and selfrepresentations (the I and the Me of James), that are, an activation of a self-evaluative process. In their theoretical model, the authors state that people will first appraise the identity goal-relevance of a situation (i.e., does it matter for how I see myself?) and then compare its congruence with personal goals ${ }^{6}$ (i.e., Who I am and who I want to be?). Congruence will lead to positive self-conscious emotions (e.g., pride) and incongruence will lead to negative selfconscious emotions (e.g., shame, guilt, embarrassment). Note also the important role of attributions in this model to predict specific emotions. For example the authors propose that attributions to stable and global aspects of the self will elicit shame, and that attributions to unstable and specific aspects of the self will elicit guilt. This is coherent with other points of view such as that of Tangney (1992) who states that guilt appears when the violation of one owns standards comes from oneself (or one's own behavior) and shame appears when the violation comes for one's global character.

This is also and above all coherent with the literature on stigma and identity and as such could easily fit our model. Indeed, studies tend to show that people who have a controllable stigma (or a stigma that is thought to be controllable) tend to blame themselves for discrimination, and feel ashamed and guilty. This is the case of people with mental illnesses (Stier and Hinshaw, 2007), of jobless people (Herman, 2007) or of people suffering of obesity. Crocker et al. (1993) showed for example that overweight women attributed rejection from a man more to their weight than to external factors (i.e., the men's prejudice toward overweight people) and that this

${ }^{6}$ Note that according to the authors, an event may be appraised as identity-goal relevant because it activates an actual, ideal or ought self; a past, present or future self; and a private or public aspect of self. We did not make this distinction in our model focusing instead on the integrity and positivity of identity, but agree that those other self-representations can also be threatened and elicit appraisal and coping. 
"auto-blame" contributed to their lower self-esteem. This is also the case of some visible stigmas because they are considered as deviant from a norm, such as body deformations due to HIV (Persson, 2005). These persons do not react in the same way to discrimination that people who have an uncontrollable stigma.

In our model, we made the distinction between what in a situation is tangible and can be dealt with and what it means for identity. This distinction would be also pertinent if we want to include emotions. So for example, basic emotions can be elicited when encountering a specific situation (e.g., discrimination) and be dependent of the characteristics of the situation and the individual. A situation appraised as being particularly unjust will engender more anger than a situation appraised as justified (e.g., because based on my overweight). Once I think that my identity is at stake in this situation, self-conscious emotions can also be elicited. Threat appraisal might engender negative self-conscious emotions such as guilt or shame, while challenge appraisal might engender positive ones such as pride. The specific self-conscious emotions that will arise will depend on the kind of attribution I make regarding my identity (as proposed by Tracy and Robins, 2004) and on the aspect of self that is under threat (e.g., as proposed by Tangney, 2003). As for appraisal concerning the social aspect of identity, we can imagine that the same self-conscious emotions can be elicited.

So emotions and self-conscious emotions can well fit in this model. Unfortunately, there is too few investigations to make precise predictions about what kind of specific emotion will be experienced by people. More research is needed in that domain, which will surely help to better understand the reactions of people facing identity threats. One piste of research could be to work on the effects of self-conscious emotion on the choice of coping strategies. For example, Tangney (2002) reported research that tend to show that while shame leads to attempts to deny, hide, or escape, guilt leads to reparative actions such as confessing or undoing.

\section{CONCLUSION}

To conclude this paper, we would like to highlight the pertinence of our model in the school context. As we explained before, this context concentrate in itself a high number of identity relevant situations. The first reason is because this context is by definition an evaluative context. Students are continually tested, evaluated,

\section{REFERENCES}

Adams, G., Tormala, T. T., and O'Brien, L. T. (2006). The effect of self-affirmation on perception of racism. J. Exp. Soc. Psychol. 42, 616-626.

Allison, K. W. (1998). "Stress and oppressed social category membership," in Prejudice: The Target's Perspective, eds. J. K. Swim and C. Stangor (San Diego, CA: Academic Press), 145-170.

Allport, G. W. (1954). The Nature of Prejudice. New York: Addison-Wesley.

Alter, A. L., Aronson, J., Darley, J. M., Rodriguez, C., and Ruble, D.N. (2010). Rising to the threat: reducing stereotype threat by reframing the threat as a challenge. J. Exp. Soc. Psychol. 46, 166-171.
Amirkhan, J. H. (1990). A factor analytically derived measure of coping: the Coping Strategy Indicator. J. Pers. Soc. Psychol. 59, 1066-1074.

Aronson, J., Fried, C. B., and Good, C. (2002). Reducing the effects of stereotype threat on African American college students by shaping theories of intelligence. J. Exp. Soc. Psychol.38, 113-125.

Ashmore, R. D., Deaux, K,, and McLaughlin-Volpe, T. (2004). An organizing framework for collective identity: articulation and significance of multidimensionality. Pers. Soc. Psychol. Bull. 130, 80-114.

Barnes, P. W., and Lightsey, O. R. Jr. (2005). Perceived racist discrimination, coping, stress and life

observed on their competence in different domains (e.g., intelligence, sport). This makes a lot of situations where one's identity can be potentially threatened and/or challenged. School is a place where basic psychological needs (e.g., needs for autonomy, competence, and relatedness; see Deci and Ryan, 2008) can or cannot be fulfilled and are regularly thwarted. Understand how students react to those threats and how it can impacts their achievement, their motivation (Urdan and Turner, 2005) and more generally their psychological adjustment is central in that context.

The second reason is that school is a social place, a place in which we meet not only teachers but also peers, who judge us, but are also, especially during adolescence a foundation for identity development (Wentzel, 2007). Beliefs about the self, how competent academically and socially we think we are, depend on positive peer relationships. Peers are also a important source of support. They bring help, advice, and information that help student to learn (Wentzel, 2007) and often represent one of the first chosen group identity a child can have.

The third reason is that school is a place where all kind of people come to study. Those are members of groups, sometimes stigmatized groups, and as such are potentially the victims of prejudice, discrimination, self-fulfilling prophecies, or stereotype threat (see Graham and Hudley, 2007; Hyde and Durik, 2007, for a discussion about the effects of gender and ethnicity in the school context).

We hope with this model to reconcile two fruitful but nevertheless quite separate literatures, the one on stress and coping and the other on identity and self. On the one hand, because all situations are not equal in regards to stress. Some concern the individual, his survival and well-being; others concern more specifically his identity and self. Models on stress and coping that can be used to explain the first ones cannot be directly applied to explain the others. On another hand, because the literature on identity threats and their consequences deserves more modelization. Our model is one attempt among others to put together and conceptualize literature on identity threats. The aim is to better understand the specificities and communities of those identity relevant situations. Even if an effort on tool development has still to be made, especially to assess appraisal and coping strategies, we hope that this attempt will help researchers, practitioners, and educators to get a more synthesized and applicable vision of the way people face and cope with identity threats.

satisfaction. J. Multicult. Counsell. Dev. 33, 48-61.

Baumeister, R. F. (1982). Self-esteem, selfpresentation, and future interaction: a dilemma of reputation. J. Pers. 50, 29-45.

Baumeister, R. F. (1998). “The self," in Handbook of Social Psychology, eds D. Gilbert, S. T. Fiske, and G. Lindzey (Boston, MA:McGraw-Hill), 680-740.

Baumeister, R. F., and Jones, E. E. (1978) When self-presentation is constrained by the target's knowledge: consistency and compensation. J. Pers. Soc. Psychol. 36, 608-618.

Berjot, S. (2003). Qui dit que je ne suis pas intelligent? Stratégies de mobilité individuelle et de créativité sociale chez les cibles stigmatisées selon la saillance du contexte menaçant: personnel ou social (Who says I'm not intelligent? The use individual mobility and social creativity by stigmatized individuals according to the type of threat: personal or social). N. Rev. Soc. Psychol. 3, 297-309.

Berjot, S., and Drozda-Senkowska, E. (2003). Stratégies de disconfirmation du stéréotype et performances des cibles stigmatisées (Strategies of stereotype disconfirmation and performance of stigmatized targets). Cahiers Internationaux de Psychologie Sociale 59, 7-21.

Berjot,S., andDrozda-Senkowska,E.(2007). Comment les étudiants se perçoiventils en fonction de leur origine sociale? Etude de contenu du stéréotype (How 
students perceive themselves according to their social origin? Study of the content of the stereotype). Eur. Rev. Appl. Psychol. 57, 119-132.

Berjot, S., and Girault-Lidvan, N. (2009). L'échelle d'Evaluation Cognitive Primaire 'Trait' (The 'trait' primary cognitive appraisal scale). Can. J. Behav. Sci. 58, 418-434.

Berjot, S., Girault-Lidvan, N., and Battaglia, N. (2008). "Stress et faire face à la discrimination et à la stigmatisation: vers un modèle du faire-face aux menaces de l'identité," (Stress and coping with discrimination and stigmatisation: toward a model of coping with identity threats), in Stress, Santéet Société(Stress, Health and Society), Vol. 4, eds. S. Berjot and B. Paty (Reims: Espur), 235-273.

Berjot, S., Girault-Lidvan, N., Bétremont, L., and Gillet, N. (2009). "Stress and coping with identity threats," in 23rd Annual Conference of the European Health Psychological Society, September 2009, Pisa, Italy.

Berjot, S., Girault-Lidvan, N., Scharnitsky, P., and Gillet, N. (2010). Comment les étudiants français d'origine maghrébine évaluent et font face à la menace de stéréotype. Application du modèle transactionnel du stress à la menace de stéréotype (How students from North African origins appraise and cope with stereotype threat: application of the transactional model of stress to the study of stereotype threat). L'Année Psychologique 110, 427-451.

Blanz, M., Mummendey, A., Mielke, R., and Klink, A. (1998). Responding to negative social identity: a taxonomy management strategies. Eur. J. Soc. Psychol. 28, 697-729.

Blascovich, J. Mendes, W. B., Hunter, S. B., and Licker, B. (2000). "Stigma, threat, and social interactions," in The Social Psychology of Stigma, eds T. F. Heatherton, R. E. Kleck, M. R. Hebl, and J.G. Hull (New York: The Guilford Press), 307-333.

Blascovich, J., Spencer, S. J., Quinn, D., and Steele, C. (2001). African Americans and high blood pressure: the role of stereotype threat. Psychol. Sci. 12, 225-229.

Bourguignon, D., Seron, E., Yzerbyt, V., and Herman, G. (2006). Perceive group and personal discrimination: differential effects on personal self-esteem. Eur. J. Soc. Psychol. 36, 773-789.

Branscombe, N. R., and Ellemers, N. (1998). "Coping with group-based discrimination: individualistic versus group level strategies," in The Social Psychology of Stigma, eds. T. F. Heatherton, R. E. Kleck, M. R. Hebl, and J.G. Hull (New York: The Guilford Press), 243-266.
Branscombe, N. R., Schmitt, M. T., and Harvey, R. D. (1999). Perceiving pervasive discrimination among African Americans: implications for group identification and well-being. J. Pers. Soc. Psychol. 77, 135-149.

Cialdini, R. B., and Richardson, K. D. (1980). Two indirect tactics of image management: basking and blasting. $J$. Pers. Soc. Psychol. 39, 406-415.

Clark, R., Anderson, B., Clark, V. R., and Williams, D. R. (1999). Racism as a stressor for African Americans: a biopsychosocial model. Am. Psychol. 54, 805-816.

Cohen, G. L., and Garcia, J. (2005). "I Am Us": negative stereotypes as collective threats. J. Pers. Soc. Psychol. 89, 566-582.

Cohen, S., Kamarck, T., and Mermelstein, R. (1983). A global measure of perceived stress. J. Health Soc. Behav. 24, 385-396.

Compas, B. E., Connor-Smith, J. K, Saltzman, H., Thomsen, A. H., and Wadsworth, M. E. (2001). Coping with stress during childhood and adolescence: problems, progress, and potential in theory and research. Psychol. Bull. 127, 87-127.

Crandall, C. S. (1994). Prejudice against fat people: ideology and self-interest. J. Pers. Soc. Psychol. 66, 882-894.

Crocker, J., Cornwell, B., and Major, B. (1993). The stigma of overweight: affective consequences of attributional ambiguity. J. Pers. Soc. Psychol. 64, 60-70.

Crocker, J., and Major, B. (1989). Social stigma and self-esteem: the selfprotective properties of stigma. Psychol. Rev. 96, 608-630.

Crocker,J., Major, B., and Steele, C. (1998). "Social stigma," in Handbook of Social Psychology, eds D. T. Gilbert, S. T. Fiske, and G. Lindzey (Boston: McGrawHill), 504-553.

Deaux, K., and Ethier, K. A. (1998). "Negotiating social identity," in Prejudice: The Target's Perspective, Chap. 14, eds J. K. Swim and C. Stangor (San Diego, CA: Academic Press), 301-323.

Deaux, K., Reid, A., Mizrahi, K., and Ethier, K. A. (1995). Parameters of social identity. J. Pers. Soc. Psychol. 68, 280-291.

Deci, E. L., and Ryan, R. M. (1985). The general causality orientations scale: self-determination in personality. $J$. Res. Pers. 19, 109-134.

Deci, E. L., and Ryan, R. M. (2008). Facilitating optimal motivation and psychological well-being across life's domains. Can. Psychol. 49, 14-23.

Diaz, R. M., Ayala, G., Bein, E., Henne, J., and Marin, B.V. (2001). The impact of homophobia, poverty, and racism on the mental health of gay and bisexual
Latino men. Am. J. Public Health 91, 927-932.

Dweck, C. S. (1999). Self-Theories: Their Role in Motivation, Personality, and Development. Philadelphia, PA: Psychology Press.

Finez, L. (2008). Comprendre et prédire les stratégies d'auto-handicap revendiqué dans le domaine du sport: une approche interactionniste. Unpublished doctoral dissertation, Université de Reims Champagne-Ardenne.

Finez, L., and Berjot, S., Rosnet, E., and Clevland, C. (in press). Do athletes claim handicaps in low ego-threat conditions? Re-examining the effect of ego-threat on claimed selfhandicapping. Sport Psychol.

Fisher, C. B., Wallace, S. A., and Fenton, R. E. (2000). Discrimination distress during adolescence. J. Youth Adolesc. 29, 679-695.

Folkman, S. (1984). Personal control and stress and coping processes: a theoretical analysis. J. Pers. Soc. Psychol. $46,839-852$.

Folkman, S., and Lazarus, R. S. (1980). An analysis of coping in a middleaged community sample. J. Health Soc. Behav. 21, 219-239.

Folkman, S., and Lazarus, R. S. (1985). If it changes it must be a process: study of emotion and coping during three stages of a college examination. J. Pers. Soc. Psychol. 48, 150-170.

Frable, D. E. (1993). Being and feeling unique: statistical deviance and psychological marginality. J. Pers. 61, 85-110.

Gaertner, L., Sedikides, C., Vevea, J. L., and Iuzzini,J. (2002). The "I", the "we", and the "when": a meta-analysis of motivational primacy in self-definition. $J$. Pers. Soc. Psychol. 83, 574-591.

Goffman, E. (1963). Stigma: Notes on the Management of Spoiled Identity. Englewood Cliffs, NJ: Prentice Hall.

Graham, S., and Hudley, C. (2007). "Race and ethnicity in the study of motivation and competence," in Handbook of Competence and Motivation, eds J. Elliot and C. S. Dweck (New York, NY: The Guilford Press), 392-413.

Harrell, J. P., Hall, S., and Taliaferro, J. (2003). Physiological responses to racism and discrimination: an assessment of the evidence. Am. J. Public Health 93, 243-248.

Haslam, S. A., O’Brien, A., Jetten, J., Vormedal, K., and Penna, S. (2005). Taking the strain: social identity, social support and the experience of stress. Br. J. Soc. Psychol. 44, 355-370.

Hegarty, P., and Golden, A. M. (2008). Attributional beliefs about the controllability of stigmatized traits: antecedents or justifications of prejudice? J. Appl. Soc. Psychol. 38, 1023-1044.
Herman, G. (ed.). (2007). Travail, Chômage et stigmatisation: Une analyse psychosociale. Bruxelles: De Boeck.

Hirt, E. R., Deppe, R. K., and Gordon, L. J. (1991). Self-reported versus behavioral self-handicapping: empirical evidence for a theoretical distinction. J. Pers. Soc. Psychol. 61, 981-991.

Hodgins, H. S., and Knee, C. R. (2002). "The integrating self and conscious experience," in Handbook of SelfDetermination Research, eds E. L. Deci and R. M. Ryan (Rochester, NY: University of Rochester Press), 87-100.

Hodgins, H. S., Weibust, K. S., Weinstein, N., Shiffman, S., Miller, A., Coombs, G., and Adair, K. C. (2010). The cost of self-protection: threat response and performance as a function of autonomous and controlled motivations. Pers. Soc. Psychol. Bull. 36, 1101-1114.

Hodgins, H. S., Yacko, H., and Gottlieb, E. (2006). Autonomy and nondefensiveness. Motiv. Emot. 30, 283-293.

Hogg, M. (2003). "Social identity," in Handbook of Self and Identity, eds M. R. Leary and J. P. Tangney (New York: The Guilford Press), 462-491.

Hong, Y.-Y., Chiu, C.-Y., Dweck, C. S., Lin, D. M.-S., and Wan, W. (1999). Implicit theories, attributions, and coping: a meaning system approach. J. Pers. Soc. Psychol. 77, 588-599.

Huguet, P., and Régnier, I. (2007). Stereotype threat among schoolgirls in quasi-ordinary classroom circumstances. J. Educ. Psychol. 99, 545-560.

Hyde, J. S., and Durik, A. M. (2007). "Gender, competence, and motivation," in Handbook of Competence and Motivation, eds J. Elliot and C. S. Dweck (New York, NY: The Guilford Press), 375-391.

Inzlicht, M., Aronson, J., Good, C., and McKay, K. (2006). A particular resiliency to threatening environments. J. Exp. Soc. Psychol. 42, 323-336.

Inzlicht, M., and Ben-Zeev, T. (2000). A threatening intellectual environment: why females are susceptible to experiencing problem-solving deficits in the presence of males. Psychol. Sci.11, 365-371.

Jarry, J. L., and Kossert, A. L. (2007). Selfesteem threat combined with exposure to thin media images leads to body image compensatory self-enhancement. Body Image 4, 39-50.

Jones, E. E., and Berglas, S. (1978). Control of attributions about the self through self-handicapping strategies: the appeal of alcohol and the role of underachievement. Pers. Soc. Psychol. Bull. 4, 200-206.

Jussim, L., and Harber, K. D. (2005). Teacher expectations and selffulfilling prophecies: knowns and unknowns, resolved and unresolved 
controversies. Pers. Soc. Psychol. Rev. 9, 131-155.

Jussim, L., Palumbo, P., C., Madon, S., and Smith, A. (2000). "Stigma and self-fulfilling prophecies," in The Social Psychology of Stigma, eds T. F. Heatherton, R. E. Kleck, M. R. Hebl, and J.G. Hull (New York: The Guilford Press), 307-333.

Jussim, L., Robustelli, S., and Cain, T. R. (2009). "Teacher expectations and selffulfilling prophecies," in Handbook of Motivation at School, eds K. R. Wenzel and A. Wigfield (New York, NY: Routledge/Taylor \& Francis Group), 349-380.

Kaiser, C. R., and Miller, C. T. (2004). A stress and coping perspective on confronting sexism. Psychol. Women Q. 28, 168-178.

Klein, O., and Azzi,A.E. (2001). The strategic confirmation of meta-stereotypes: how group members attempt to tailor an out-group's representation of themselves. Br. J. Soc. Psychol. 40, 279-293.

Knee, C. R., Lonsbary, C., Canevello, A., and Patrick, H. (2005). Selfdetermination and conflict in romantic relationships. J. Pers. Soc. Psychol. 89, 997-1009.

Kobrynowicz, D., and Branscombe, N. R. (1997). Who considers themselves victims of discrimination? Individual difference predictors of perceived gender discrimination in women and men. Psychol. Women Q. 21, 347-363.

Lazarus, R. S. (1991). Emotion and Adaptation. New York: Oxford University Press.

Lazarus, R. S. (1999). Stress and Emotion: A New Synthesis. New York, NY: Springer.

Lazarus, R. S. (2006). Emotions and interpersonal relationships: toward a person-centered conceptualization of emotions and coping. J. Pers. 74, 9-46.

Lazarus, R. S., and Folkman, S. (1984). Stress, Appraisal and Coping. New York: Springer.

Leary, M. R. (2007). Motivational and emotional aspects of the self. Annu. Rev. Psychol. 58, 317-344.

Lemaine, G. (1974). Social differentiation and social originality. Eur. J. Soc. Psychol. 4, 17-52.

Major, B., McCoy, S. K., Kaiser, C. R., and Quinton, W. J. (2003a). "Prejudice and self-esteem: a transactional model," in European Review of Social Psychology, Vol. 14, eds W. Strobe and M. Hewstone (London: Psychology Press), 77-104.

Major, B., Quinton, W. J., and Schmader, T. (2003b). Attributions to discrimination and self-esteem: impact of group identification and situational ambiguity. J. Exp. Soc. Psychol. 39, 220-231.
Major, B., and O'Brien, L. T. (2005). The social psychology of stigma. Annu. Rev. Psychol. 56, 393-421.

Martens, A., Johns, M., Greenberg, J., and Schimel, J. (2005). Combating stereotype threat: the effect of selfaffirmation on women's intellectual performance. J. Exp. Soc. Psychol. 42, 236-243.

Marx, D. M., and Stapel, D. A. (2006). Distinguishing stereotype threat from priming effects: on the role of the social self and threat-based concern. J. Pers. Soc. Psychol. 91, 243-254.

McQueen, A., and Klein, W. M. P. (2006). Experimental manipulations of selfaffirmation: a systematic review. Self Identity 5, 289-365.

Mendoza-Denton, R., Downey, G., Purdie, V. J., Davis, A., and Pietrzak, J. (2002). Sensitivity to status-based rejection: implications for African American students' college experience. J. Pers. Soc. Psychol. 83, 896-918.

Menec, V. H., and Perry, R. P. (1998). Reactions to stigmas among Canadian students: testing attribution-affecthelp judgment model. J. Soc. Psychol. $138,443-453$.

Miller, C. T., and Kaiser, C. R. (2001). A theoretical perspective on coping with stigma. J. Soc. Issues 57, 73-92.

Miller, C. T., and Major, B. (2000). "Coping with stigma and prejudice," in The Social Psychology of Stigma, eds T. F. Heatherton, R. E. Kleck, M. R. Hebl, and J.G. Hull (New York: The Guilford Press), 243-272.

Mummendey, A., Klink, A., Mielke, R., Wenzel, M., and Blanz, M. (1999). Socio-structural characteristics of intergroup relations and identity management strategies: results from a field study in East Germany. Eur. J. Soc. Psychol. 29, 259-285.

Nussbaum, A. D., and Dweck, C.S. (2008). Defensiveness versus remediation: self-theories and modes of self-esteem maintenance. Pers. Soc. Psychol. Bull. 34, 599-612.

Osborne, J. W. (2006).Gender, stereotype threat, and anxiety: psychophysiological and cognitive evidence. Electron. J. Res. Educ. Psychol. 4, 109-138.

Osborne, J.W. (2007). Linking stereotype threat and anxiety. Educ. Psychol. 27, 135-154.

Persson, A. (2005). Facing HIV: body shape change and the (in) visibility of illness. Med. Anthropol. 24, 237-264.

Pinel, E. C. (1999). Stigma consciousness: the psychological legacy of social stereotypes. J. Pers. Soc. Psychol. 76, 114-128.

Pinel, E. C. (2002). Stigma consciousness in intergroup contexts: the power of conviction. J. Pers. Soc. Psychol. 38, 178-185.
Rattan, A., and Dweck, C. S. (2010). Who confronts prejudice?: the role of implicit theories in the motivation to confront prejudice. Psychol. Sci. 21, 952-959.

Rector, N. A., and Roger, D. (1997). The stress buffering effects of self-esteem. Pers. Individ. Dif. 23, 799-808.

Rhodewalt, F. (1990). "Self-handicappers: individual differences in the preference for anticipatory, self-protective acts," in Self-Handicapping: The Paradox That Isn't, eds R. L. Higgins, C. R. Snyder, and S. Berglas (New York: Plenum Press), 69-106.

Richman, L. S., Bennett, G. G., Pek, J., Siegler, I., and Williams, R. B. Jr. (2007). Discrimination, dispositions and cardiovascular responses to stress. Health Psychol. 26, 675-683.

Roth, S., and Cohen, L. (1986). Approach, avoidance, and coping with stress. Am. Psychol. 41, 813-819.

Sander, D., and Scherer, K. R. (2009). "La psychologie des emotions: survol des theories et débats essentiels," in Traité de psychologie des émotions, eds D. Sander and K. R. Scherer (Paris: Dunod), 1-40.

Scheepers, D., and Ellemers, N. (2005). When the pressure is up: the assessment of social identity threat in low and high status groups. J. Exp. Soc Psychol. 41, 192-200.

Schmitt, M. T., and Branscombe, N. R. (2002). "The meaning and consequences of perceived discrimination in disadvantaged and privileged social groups," in European Review of Social Psychology, Vol. 12, eds W. Stroebe and M. Hewstone (London: Psychology Press), 167-199.

Sedikides, C. (1993). Assessment, enhancement, and self-verification determinants of the self-evaluation process. $J$. Pers. Soc. Psychol. 65, 317-338.

Sedikides, C., and Gregg, A. P. (2003) "Portraits of the self," in Sage Handbook of Social Psychology, eds M. A. Hogg and J. Cooper (London: Sage), 110-138.

Sedikides, C., and Strube, M.J.(1997). "Selfevaluation: to thine own self be good, to thine own self be sure, to thine own self be true, and to thine own self be better," in Advances in Experimental Social Psychology, Vol. 29, ed. M. Zanna (San Diego, CA: Academic Press), 209-269.

Sekaquaptewa, D., and Thompson, M. (2002). The differential effects of solo status on members of high- and lowstatus groups. Pers. Soc. Psychol. Bull. 28, 694-707.

Shapiro, J. R., and Neuberg, S. L. (2007), From stereotype threat to stereotype threats: implications of a multi-threat framework for causes, moderators, mediators, consequences, and interventions. Pers. Soc. Psychol. Rev $11,107-130$.
Siegal, K., Lune, H., and Meyer, I. H. (1998). Stigma management among gay/bisexual men with HIV/AIDS. Qual. Sociol. 21, 3-24.

Skinner, C., and Brewer, N. (2002). The dynamics of threat and challenge appraisals prior to stressful achievement events. J. Pers. Soc. Psychol. 84, 60-70.

Skrypneck, B. J., and Snyder, M. (1982). On the self-perpetuating nature of stereotypes about women and men. J. Exp. Soc. Psychol. 18, 277-291.

Steele, C. M. (1988). "The psychology of self-affirmation: sustaining the integrity of the self," in Advances in Experimental Social Psychology, Vol.21, ed. L. Berkowitz (New York: Academic Press), 261-302.

Steele, C. M. (1997). A threat in the air: how stereotypes shape intellectual identity and performance. Am. Psychol. 52, 613-629.

Steele, C. M., and Aronson, J. (1995). Stereotype threat and the intellectual test performance of African Americans. J. Pers. Soc. Psychol. 69, 797-811.

Stier, A., and Hinshaw, S. P. (2007). Explicit and implicit stigma against individuals with mental illness. Aust. Psychol. 42, 106-117.

Stone, J. (2002). Battling doubt by avoiding practice: the effects of stereotype threat on self-handicapping in white athletes. Pers. Soc. Psychol. Bull. 28, 1667-1678.

Suls, J., and Fletcher, B. (1985). The relative efficacy of avoidant and nonavoidant coping strategies: a metaanalysis. Health Psychol. 4, 249-288.

Swim, J. K., Hyers, L. L., Cohen, L. L., and Ferguson, M. J. (2001). Everyday sexism: evidence for its incidence, nature, and psychological impact from three daily diary studies. J. Soc. Issues 57 , 31-53.

Tajfel, H. (1978). Differentiation Between Social Groups: Studies in the Social Psychology of Intergroup Relations. London: Academic Press.

Tajfel, H. (1981). Human Groups and Social Categories: Studies in Social Psychology. Cambridge: Cambridge University Press.

Tajfel, H., and Turner, J. C. (1986). “The social identity theory of intergroup behavior," in The Psychology of Intergroup Relations, eds S. Worchel and W. G. Austin (Chicago: NelsonHall), 7-24.

Tangney, J. P. (1992). Situational determinants of shame and guilt in young adulthood. Pers. Soc. Psychol. Bull. 18, 199-206.

Tangney, J. P. (2003). “Self-relevant emotions," in Handbook of Self and Identity, eds M. R. Leary and J. P. Tangney (New York: Guilford), 384-400. 
Tracy, J. L., and Robins, R. W. (2004). Putting the self into self-conscious emotions: a theoretical model. Psychol. Inq. 15, 103-125.

Turner, J. C. (1982). "Toward a cognitive redefinition of the social group," in Social Identity and Intergroup Relations, ed. H. Tajfel (Cambridge: Cambridge University Press), 5-40.

Turner, J. C., Hogg, M. A., Oakes, P. J., Reicher, S. D., and Wetherell, M. S. (1987). Rediscovering the social group: a self-categorization theory. Oxford: Basil Blackwell.

Urdan, T., and Turner, J. C. (2005). "Competence motivation in the classroom," in Handbook of Competence and Motivation, eds A. E. Andrew and C. S. Dweck (New York, NY: Guilford Publications), 297-317. Weiner, B., Perry, R. P., and Magnusson, J. (1988). An attributional analysis of reactions to stigmas. J. Pers. Soc. Psychol. 55, 738-748.

Wentzel, K. R. (2007). "Peer relationships, motivation, and academic performance at school," in Handbook of Competence and Motivation, eds J. Elliot and C. S. Dweck (New York, NY: The Guilford Press), 279-296.

Wheeler, S. C., and Petty, R. E. (2001). The effects of stereotype activation on behaviour: a review of possible mechanisms. Psychol. Bull. 127, 797-826.

Wout, D., Danso, H., Jackson, J., and Spencer, S. (2008). The many faces of stereotype threat: group and self-threat. J. Exp. Soc. Psychol. 44, 792-799.

Conflict of Interest Statement: The authors declare that the research was conducted in the absence of any commercial or financial relationships that could be construed as a potential conflict of interest.

Received: 21 December 2010; paper pending published: 07 January 2011; accepted:
16 February 2011; published online: 01 March 2011.

Citation: Berjot S and Gillet N (2011) Stress and coping with discrimination and stigmatization. Front. Psychology. 2:33. doi: 10.3389/fpsyg.2011.00033

This article was submitted to Frontiers in Educational Psychology, a specialty of Frontiers in Psychology.

Copyright (C) 2011 Berjot and Gillet. This is an open-access article subject to an exclusive license agreement between the authors and Frontiers Media SA, which permits unrestricted use, distribution, and reproduction in any medium, provided the original authors and source are credited. 